\section{MEMORIA Y RESILIENCIA* Estudio de la memoria de las victimas del conflicto armado en el departamento del magdalena: presentificacion, visibilizacion, catarsis y resiliencia}

\author{
Edimer Leonardo Latorre Iglesias ${ }^{* *}$
}

Fecha de Recepción: 28 de Mayo de 2010

Fecha de Aceptación: 31 de Mayo de 2010

Artículo de Reflexión

\section{Resumen}

Las víctimas de la violencia en el Departamento del Magdalena han sido silenciadas por el olvido sistemático del gobierno, de la sociedad en general y de los medios masivos de comunicación, que al establecer sus agendas de contenidos, no tienen en cuenta el sufrimiento casi permanente de los tradicionalmente excluidos de la sociedad. En ese proceso de negación constante y de aplazamiento de los derechos de las personas en condición de desplazados forzosos, las víctimas de la violencia desarrollan interna y externamente resiliencia. El presente artículo, retoma de forma general los aspectos claves de la investigación, sobre memoria y resiliencia que actualmente desarrolla la Escuela

Este artículo es un avance que pertenece a la investigación sobre memoria y resiliencia (2009-2010) que actualmente está desarrollando la Escuela de Comunicación social y periodismo de la Universidad Sergio Arboleda a través del grupo de investigación comunicación y sociedad.

** Sociólogo de la Universidad de Antioquia, especialista en Docencia Universitaria, Docente investigador de la Escuela de Comunicación Social y periodismo de la Universidad Sergio Arboleda de Santa Marta, actualmente candidato a doctor en Sociología jurídica e instituciones políticas de la Universidad Externado de Colombia. Director de la línea de investigación marginalidad y medios del grupo de investigación, comunicación y sociedad de la Universidad Sergio Arboleda en la ciudad de Santa Marta. Correo electrónico: edimer.latorre@usa.edu.co; edimerlatorre@, hotmail.com de Comunicación social y periodismo de la Universidad Sergio Arboleda seccional Santa Marta.

\section{Palabras clave}

Memoria, resiliencia, desplazamiento forzoso, víctimas de la violencia, visibilización de las víctimas.

\section{MEMORY AND RESILIENCE}

\begin{abstract}
The victims of the violence in the Magdalena Department have been silenced by the systematic neglect of the government, of the society in general and of the mass media, which on having established their priorities, do not take into account the permanent suffering of excluded people from society. In this constant, denial and postponement process of the rights of people in condition of forced displacement, the victims of the violence develop internal and external resilience. This article take the general key aspects of research, on memory and resilience that develops the School of Social Communicatios and Journalism from the Universidad Sergio Arbolelda sectional Santa Marta.
\end{abstract}

\section{Keywords}

Memory, resilience, forced displacement, victims of the violence, visibilizacion of the victims.

\section{A MANERA DE INTRODUCCION}

"Si la vida es el original, el recuerdo es una copia del original y el apunte una copia del recuerdo. Pero ¿Qué queda de la vida cuando uno no la recuerda ni la escribe? Nada. Hay muchos pedazos de nuestra vida que ya no son nada, por un simple hecho: porque ya no los recordamos. Todo lo que no se recuerda ha desaparecido para siempre.

La vida tiene la misma consistencia de los sueños que, al despertarnos, se desvanecen. Por eso uno 
debería tener con ciertos episodios de la vida -tal como hacemos a veces con algunos sueños- la precaución de anotarlos porque si no se olvidan y se disuelven en el aire" ${ }^{1 "}$.

La guerra contra la muerte es también una guerra contra el olvido, los seres humanos inventamos la cultura y la vida social para poder ganar la guerra contra el olvido, pero paradójicamente la vida contemporánea se caracteriza por ser una vida liquida ${ }^{2}$, una vida rápida y por ende un pensar rápido, un pensar que implica prácticamente un no pensar ${ }^{3}$, pareciera que en las sociedades postmodernas o postindustriales no hay tiempo para el recuerdo y que la amnesia fuera atrapada por el sin sentido de las interrelaciones de la vida social.

Las personas víctimas de la violencia en Colombia no solo deben enfrentarse a perder la vida, sino que también deben esforzarse al máximo porque no se olvide en la memoria colectiva sus tragedias, sus pesares, y sobre todo deben confrontar las estructuras burocráticas para que sean reconocidos y materializados sus derechos, aplazados y postergados históricamente. El artículo que se lee a continuación es un avance de investigación que da cuenta del proceso de reconstrucción, mediante metodologías cualitativas, de la memoria de las víctimas de la violencia en el Departamento del Magdalena, con la intención de evidenciar los procesos de resiliencia y analizar la forma como se materializa la resiliencia a partir de la resignificación de la memoria.

FACIOLINCE, Héctor Abad. Traiciones de la memoria. Alfaguara. Bogotá. 2009. p. 15.

2 BAUMAN, Zygmunt. Vida de consumo. Fondo de Cultura Económica. México. 2003.

3 SARTORI, Giovanni. El homo videns: La sociedad teledirigida. Santillana-Taurus. Madrid. 1998.

\section{EL PROBLEMA DE INVESTIGACION}

E1 22 de noviembre de 2000 a las 9 y 30 de la noche, un escuadrón de la muerte fuertemente armado perteneciente a los paramilitares dirigidos por Rodrigo Puppo, alias "Jorge 40", hizo su aparición en el pueblo de Nueva Venecia, corregimiento del municipio de Sitio Nuevo, Departamento del Magdalena, asesinando con lista en mano a 60 pescadores. Las características y el accionar del escuadrón de la muerte así como los hechos y el desarrollo de la masacre, indiscutiblemente se ajusta a los parámetros de los grupos paramilitares en Colombia, como lo reseña la Comisión Interamericana de Derechos Humanos de la Organización de Estados Americanos:

"... la forma como fueron asesinadas las victimas es propia de la acción paramilitar, ya que fueron asesinadas con un tiro de fusil dirigido a la cabeza y a corta distancia. Este tipo de fusilamiento ocasiona el efecto "tormenta de nieve", según el cual el proyectil entra y asciende en forma de espiral desfigurando totalmente el rostro de las víctimas, con desprendimiento de fosa craneana y destrucción facial. Este modus operandi corresponde a las acciones realizadas por grupos paramilitares con el objetivo de generar terror, desolación y silencio en la población"4.

Según el Equipo NIZKOR ${ }^{5}$, al despedirse los paramilitares dejaron cadáveres al frente de la iglesia cubiertos con una sábana blanca que tenia escrito en letras de sangre: "Ahí les dejo los aguinaldos, que tengan una feliz navidad". Esta masacre genero un desplazamiento de más de 3000 personas a los corregimientos colindantes. E1 Estado, a pesar de los múltiples

4 COMISION INTERAMERICANA DE DERECHOS HUMANOS. Informe No 88/06. Petición 1306-05. Organización de Estados Americanos. 2006. p. 7.

5 EQUIPO NIZKOR. Informe de la comisión de organismos de Derechos humanos sobre la masacre en la ciénaga grande de Santa Marta. Bogotá. 2000. 
llamados de auxilio, solo hizo presencia militar en la zona 5 días después.

Aunado a la barbarie anterior, el Departamento del Magdalena ha enfrentado en la década que va de 1999 a 2009, diversos y múltiples conflictos, producto del entrechocar de actores armados. Las guerras entre facciones paramilitares por el control de la Sierra Nevada de Santa Marta, el enfrentamiento entre paramilitares y guerrilla, el enfrentamiento entre las guerrillas del ELN y las FARC por el dominio de los corredores para el transporte de la droga, así como el enfrentamiento entre agentes del estado y las diversas expresiones del conflicto armado, han propiciado una escalada de la violencia y una gran cantidad de víctimas.

Solamente entre 1999 y 2005 el Departamento del Magdalena tuvo 127.767 nuevos desplazados y su capital Santa Marta, recibió en ese mismo lapso de tiempo 76.957 desplazados ${ }^{6}$. El Magdalena presenta unas cifras sobre crecimiento económico y competitividad que hacen más desolador el panorama. De 100 pesos el Departamento del Magdalena aporta al PIB 1,61 centavos ${ }^{7}$. De la lista de las mejores 3000 empresas en el país, sólo 13 pertenecen al Magdalena ${ }^{8}$. El Departamento vende más de lo que compra, por cada empleado hay tres desempleados y lo triste de ello es que estos empleados entran dentro de la categoría de ocupados pobres, es decir con baja posibilidad de consumo.

6 CONSULTORÍA PARA LOS DERECHOS HUMANOS Y EL DESPLAZAMIENTO. DEPARTAMENTOS DE LLEGADA AÑOS 2006 - 2007. Fuente: Sistema de Información sobre desplazamiento Forzado y Derechos Humanos - SISDHES. Reporte: febrero 13 de 2008.

7 DANE. Informe de coyuntura económica Regional Departamento del Magdalena. 2008.

8 DOING BUSINESS en Colombia. Banco Mundial y la corporación financiera Mundial. 2010. p. 13.
El coeficiente de concentración de tierras (0.74\%) es bastante elevado, además, tiende a desplazar mano de obra, es decir una hectárea de banano emplea a 8 trabajadores y una de palma a 2, los cultivos de palma desplazan a seis trabajadores, seis ocupados pobres que se desplazan del todo. Somos uno de los Departamentos más atrasados en construcción de vías y en dotación de alcantarillados 9 .

Las víctimas de la violencia deben ajustarse a estas realidades y sobrevivir en medio de la espiral de miseria, proceso en el cual, no solo deben lidiar con las burocracias del estado para hacer valer sus derechos ${ }^{10}$, sino con el problema más grande de todos, el del olvido ${ }^{11}$.

Paulatina y sistemáticamente las víctimas son invisibilizadas, borradas, postergadas, por 10 que hemos decidido nombrar como el triple proceso. Primero son estigmatizadas. Es decir deben portar socialmente con el lastre de ser víctimas. En segunda instancia empiezan a ser consientes de su proceso de ser víctimas, lo que los convierte en seres dependientes de la ayuda estatal (cuando esta llega), para finalmente culminar como una víctima que se olvida a sí misma, que terminar postergando sus recuerdos, sus tragedias y su dolor. Como anoto en su momento una de las habitantes de Nueva Venecia, la señora Dolores:

"Piense cómo se va reponer esta gente, acostumbrada a vivir sólo de la pesca; son seres que nacieron en el agua, viven en el agua y quieren morir en el agua. No desean que nadie los ponga a escoger o tomar partido en la guerra. ¿Qué tiene

9 DANE. Informe de coyuntura económica Regional Departamento del Magdalena. Ob. Cit.

10 LATORRE IGLESIAS, Edimer. De aplazados a desplazados: la realidad de los derechos de las personas en condición de desplazamiento forzoso en la ciudad de Santa Marta. Fondo de publicaciones Universidad Sergio Arboleda. Bogotá. 2009.

11 CAMARGO, José Antonio. Voces y silencios del desplazamiento forzado en la ciudad de Santa Marta. Universidad Sergio Arboleda. Santa Marta. 2007. 
que ver esta laguna con la guerra? Es que resulta dificil cambiarles las costumbres a las personas, aunque sus posesiones sean tan miserables: un chinchorro, una hamaca y una casa de madera sobre el agua. Pero todo eso es su vida. Estas cosas son parte nuestra, casi un miembro de nuestro cuerpo; y es impensable que nos veamos privados de ellas en nuestro mundo" 12 .

Para luego continuar:

"Ahora imaginese a estas pobres gentes desplazadas a quienes, además de sus maridos, les quitan las casas, las costumbres, las ropas; todo, literalmente todo lo que poseen: serán seres vacios, reducidos al sufrimiento y a la necesidad, faltos de dignidad y de juicio, porque quien lo ha perdido todo fácilmente se pierde a sí mismo..."13.

Es en la parte final de la narración de doña Dolores, donde adquiere podemos formular con claridad el problema de investigación que direcciona este trabajo:

¿Cual es la memoria histórica que poseen las víctimas del conflicto armado en el Departamento del Magdalena?

$\mathrm{Y}$ a partir de esta pregunta problema surge el siguiente interrogante:

¿Es factible a través de los procesos de re-significación de la memoria, construir resiliencia en las víctimas del conflicto armado en el Departamento del Magdalena?

El poder del recuerdo se constituye en poblaciones víctimas de la violencia en una forma de contrapoder, y por ende el recuerdo deviene en poder para los sujetos que resignifican a través de la presentificación de los actos. El objetivo central de la investigación en mención es que

\footnotetext{
12 Estrada, Fernando. "Ciénaga Grande: viaje al corazón de la barbarie”. En: Revista Número. No 28. 2000. Bogotá.

13 Ibidem.
}

la memoria se vuelva una herramienta contra los discursos hegemónicos de dominación y de invisibilización.

Para los hindúes, la historia se repite en un eterno retorno, y este proceso se simboliza a través de la creencia de que la historia es una serpiente que se devora a si misma por la cola. El fundamento de esta investigación estriba en que no vuelva a pasar lo que nunca debió pasar. Estamos convencidos que recordar es comprender, pero más que un simple comprender, creemos firmemente que comprender es trascender. Los ejercicios de re-significación de la memoria solo buscan generar resiliencia en las víctimas del conflicto, con el deseo ferviente de que no vuelvan a existir aguinaldos manchados de sangre y que las serpientes no devoren más, de una forma repetitiva, generando dolor y llanto.

\section{EL MÉTODO}

La investigación que en estos momentos está en curso se considera de corte descriptivo, porque sus fundamentos están enfocados en la identificación y descripción de las características esenciales, hechos o fenómenos que enmarcan la memoria de las víctimas del conflicto armado en el Departamento del Magdalena.

Al respecto Sampieri es claro cuando afirma:
"Con frecuencia, la meta del investigador consiste en describir fenómenos, situaciones, contextos y eventos; esto es, detallar como son y se manifiestan. Los estudios descriptivos buscan especificar las propiedades, las características $y$ los perfiles de personas, grupos, comunidades, procesos, objetos o cualquier otro fenómeno que se someta a un análisis. Es decir, miden, evalúan o recolectan datos sobre diversos conceptos (varia- bles), aspectos, dimensiones o componentes del fenómeno a investigar. En un estudio descriptivo se selecciona una serie de cuestiones y se mide o 
recolecta información sobre cada una de ellas, para así (valga la redundancia) describir lo que se investiga" 14.

El método de investigación que será utilizado durante todo el proceso es el analítico hermenéutico, a través del cual se pretende interpretar y validar cada una de las experiencias de los sujetos que intervienen en el proceso de re-significación de la memoria de las víctimas de la violencia por el conflicto armado en el Departamento del Magdalena. Este método posibilita comprender la particularidad de sus vivencias, sus relatos y sobre todo su historia, una historia que implica superar las concepciones tradicionales de lo histórico, no la historia de los vencedores, sino la de los vencidos y los derrotados por la violencia. Centrarnos en esta metodología propicia un descubrimiento y redescubrimiento tanto del investigador como del sujeto investigado:

"... cuando se atiende a la historia se revelan las rupturas, las continuidades, las crisis, los imaginarios y las representaciones que quizá no dijeran mucho sobre la organización de la sociedad y sus estructuras pero sí sobre los procesos de su configuración y sobre las maneras como lo sujetos pensaron y vivieron sus relaciones con el pasado $y$ sus esperanzas de futuro ${ }^{15}$ ".

Esta metodología es eminentemente cualitativa, ya que como lo plantea Pulido:

"Los procesos de la investigación cualitativa son de desarrollo en espiral o de naturaleza multiciclo, $y$ obedecen a una modalidad de diseño flexible. Esto significa que las hipótesis no son fijas a lo largo del recorrido investigativo, sino que se trabajan dentro de un enfoque heurístico o generativo, lo que indica que cada descubrimiento

14 SAMPIERI, Roberto. Metodología de la investigación. Mc Graw Hill. México. 2006. p. 102.

15 GALEANO, María Eumelia. Estrategias de investigación social cualitativa. El giro en la mirada. La Carreta. Medellín. 2004. p. 13. se convierte en el punto de partida de un nuevo ciclo investigativo dentro de un mismo proceso de investigación" ${ }^{16}$.

Este proceso de investigación se valida adicionalmente en lo que a este ejercicio particular se refiere porque:

"Esos hallazgos se validan por las vías del consenso y la interpretación de evidencias. En la investigación cualitativa se destacan los siguientes aspectos: la recuperación de la subjetividad como espacio de construcción de la vida humana, la reivindicación de la vida cotidiana como escenario básico para comprender la realidad sociocultural, la intersubjetividad y el consenso, como vehículos para acceder al conocimiento valido de la realidad humana"17.

Lo que se busca en últimas es analizar desde el sujeto la forma como se ha asumido el problema de ser víctima. Es decir, realizar un giro en la mirada, no desde lo institucional visto y publicitado, sino desde las vivencias de lo no publicitado y no publicable en el mundo mediático y si desde el sujeto que siente y vive una determinada realidad. Este giro en la mirada es entendido por Galeano como un:

“... situar la mirada en el sujeto de la acción, en sus contextos particulares con sus determinaciones históricas, sus singularidades culturales, sus diferencias y las distintas maneras de vivir y pensar sobre los grandes y los pequeños acontecimientos y situaciones por las que han cruzado sus historias personales" $"$.

Es decir, el giro en la mirada que ofrece la perspectiva cualitativa es una lectura de la realidad social desde los sujetos que vivencian dicha realidad. Para ello es que se asume el paradigma de

16 Pulido, Rodrigo. Abordaje hermenéutico de la investigación cualitativa. Editorial Universidad Cooperativa de Colombia. Bogotá. 2007. p. 26.

17 Ibidem.

18 Ibíd. p. 11. 
investigación social cualitativa que reflexiona desde y con los actores, su realidad:

"La investigación social cualitativa apunta a la comprensión de la realidad como resultado de un proceso histórico de construcción a partir de la lógica de los diversos actores sociales, con una mirada "desde adentro", y rescatando la singularidad y las particularidades propias de los procesos sociales. Los estudios cualitativos ponen especial énfasis en la valoración de lo subjetivo y lo vivencial y en la interacción entre sujetos de la investigación; privilegian lo local, lo cotidiano y lo cultural para comprender la lógica y el significado que tienen los procesos sociales para los propios actores, que son quienes viven y producen la realidad sociocultural" 19.

El enfoque cualitativo aporta también perspectiva holística, que

“... le plantea al investigador valorar los escenarios, las personas, los contextos, los grupos $y$ las organizaciones como un todo no reducible a variables. Las personas son estudiadas en el contexto de su pasado y en el de las situaciones actuales, entendiendo que el presente contiene en germinación aspectos del futuro"20.

Para alcanzar esta finalidad, se emplearan tres herramientas cualitativas en la estrategia de investigación. Inicialmente se hará observación participante a través de listas de chequeo. Los resultados de las listas de chequeo posibilitaran entender las dinámicas propias de las comunidades observadas. Esta fase nos permitirá acercarnos al objeto de investigación.

Luego se seleccionara a los líderes emblemáticos $\mathrm{y}$ tradicionales, o a las personas con relatos significativos y simbólicos dentro de lo investigado y se realizaran entrevistas semiestructuradas, las cuales nos permitirán entender (presentificar y re-significar) las diversas memorias de

\footnotetext{
$19 \quad$ Ibíd. p. 21.

20 Ibídem.
}

las víctimas del conflicto armado. Finalmente se diseñaran historias de vida en un proceso de co-implicación entre investigador e investigado.

Las fuentes orales son la base de estas dos herramientas cualitativas. Teniendo claro que la oralidad desde el sujeto es:

“... ante todo, fuentes vivas, actuantes, que constituyen una matriz compleja de producción de sentido, que se expresan mediante la vivencia, la evocación, los recuerdos, la memoria, la narración oral, entre otras. La característica sobresaliente de esta evidencia es su dimensión humana, que transmite una versión y una visión de la experiencia personal desde una situación y un medio social en el tiempo presente. Las fuentes vivas no son resurrecciones de experiencias reales sino, más bien, reconstrucciones históricas de lo vivido. Por la dimensión especificamente humana de las fuentes vivas, no interesa tanto develar lo falso y lo oculto como reconocer lo no explicito, en tanto que nos ayuda mas a comprenderlas $y$ conocerlas que a descalificarlas" 21 .

En el procesamiento de la información arrojada por las entrevistas, y en la estructuración de la historia de vida, se tendrá en cuenta lo planteado por Bourdieu:

"Su función es recordar las condiciones sociales y los condicionantes de los que es producto el autor de discurso, su trayectoria, su formación, sus experiencias profesionales, todo lo que se disimula y se revela a la vez en el discurso transcripto, pero también en la pronunciación y la entonación, borradas por la transcripción, así como en el lenguaje del cuerpo -gestos, postura, mímicas, miradas- $y$ de igual modo en los silencios, los sobreentendidos y los lapsus" 22.

21 ACEVES, Jorge. Técnicas de investigación y manipulación. Práctica y estilos de investigación en la historia oral contemporánea. Historia y fuente Oral. Barcelona. 1994. p. 226.

22 BORDIEU, Pierre. Sobre la televisión. Anagrama. Barcelona 1984. p. 8. 
La reconstrucción de las historias de vida de las víctimas, serán enmarcadas en un análisis previo donde se contextualizara la narración, tratando de conectar lo particular de la historia con el hecho en general. Es decir las narraciones individuales se enmarcaran en un contexto general.

La técnica de la reconstrucción o mejor aun de la resignificación de las historias de vida la asumimos desde la óptica de Montero:

“... el sujeto protagonista puede regresar a sus recuerdos, retomar hechos ya relatados, corregirlos, ilustrarlos, aun modificarlos, saltar de una etapa a otra de su vida en una periodización propia, detenerse en algunos aspectos y apresurarse en otros. Y a su vez, el sujeto investigador puede pedir al informante que se devuelva en su recuento para retomar un punto, un hecho, una etapa; o preguntarle directamente sobre algo en lo que el sujeto participo o fue testigo; puede señalar disparidades e indagar sobre ellas, y finalmente, al transcribir cada recuento debe someterlo a la inspección del protagonista, quien tiene todo el derecho de modificarlo" 23 .

La finalidad de este proceso de resignificación es que la victima haga una presentificación de lo ocurrido. Es decir recuerde para trascender lo recordado haciendo catarsis, expiando el dolor a partir de una reelaboración que se produce en su interior, desde un resiliencia que surge a partir del recuerdo. El objetivo clave de este proceso es el recuerdo.

"Es importante reiterar que la mayor parte de las veces recordar no es revivir, pero si rehacer, reconstruir, repensar, con imágenes e ideas de hoy las experiencias del pasado" 24 .

23 Montero, Maritza. "Historias de vida: memoria individual y colectiva". En: Revista Acta sociológica. Numero 1. Enero-Abril de 1990. Bogotá. p. 13.

24 Díaz, Carlos, et al. "Hacia la comprensión de universos Psico-Culturales. Las fuentes vivas: memoria y narración". En: SERNA, Adrian. Memorias en cri-
Veamos en esta direccionalidad el relato de un sobreviviente de la masacre del morro en nueva Venecia:

"Cuando íbamos para adentro nos decian: jahora que salgan es para matarlos! jDescansen ahi $y$ díganle adiós año nuevo! Nos dijeron ellos, como se estaba aproximando el año nuevo. Ya que nos encerraron nos van a matar, jbueno! Cuando nosotros salimos habia 18, yo me acordaba de mis hijos y me van a matar y mis hijos no van a saber, yo decía ¿quién es adivino? nada más que un solo Dios.

Cuando en eso abrieron la puerta: jbueno salgan! Ya tenían 18 acostados. Salieron como 10 adelante mío. ¡Viejo usted piérdase para allá! Cuando ellos me dijeron a mi así, yo sentí otro alivio y yo dije ya me salvé. Yo sali todo tembloroso, yo tiraba a jalarme con las manos y yo veía que no andaba nada en el agua del mismo susto no me daba ganas, yo veía que no andaba nada para llegar a la casa.

Cuando estábamos así, gritaron ;deténganse ahi!! Ahora van a ver esto, pusieron a tres caminaban, uno primero por arriba de los muertos que estaban boca abajo y los muertos cuando caminaban por encima de ellos, como ellos tenían unas botas, esos muertos hacían ruidos y uno caminaba por arriba de ellos 3 veces y fue cuando llegamos a la punta. Entonces les dijo el comandante: jaja comandante que pensamos que ya está de día!, ijuego, quiero juego! entonces les dijo el comandante a los otros.

Entonces pusieron uno aquí y uno allá y uno alla itra tra tra tra tra tra tra tra tra tra tra tra tra tra tra tra tra tra tra tra tra...! Y eso botaba candela, candela los fusiles esos botaban candela, cuando los estaban matando, yo temblaba mas ahi, yo casi que me desmayo, que me arrodillé porque ya las piernas no me daban, ya no tenía fuerzas en los huesos, ya me arrodillé. jOye párate de ahi gran pendejo párate de ahí y piérdete rapidito!

soles. Universidad Distrital Francisco José de Caldas. Bogotá. 2009. p. 89. 
Salimos como 10 que nos tiramos al agua, pasamos por un colegio por un puente y nos tiramos al agua. Bueno ahi amanecimos en la casa sin bote; entonces yo tenía a las hermanas mías que las mandé con los pelaos allá para un monte que está cerca y unos hermanos mios por qué no aguantaba con el poco de gente. Hermano lleva a las mujeres y los pelaos chiquitos, nosotros después si hay canoa nos vamos para el monte y gracias a Dios que no encontramos canoa.

Amanecimos ahi y por ahí como a las 7 de la mañana, presté una canoa a donde un vecino $y$ sali a buscar a mis hermanos en el monte y no los encontré, pero cuando yo llegué al pueblo ya estaban en el pueblo y cuando yo venía llegando al pueblo venían las 5 lanchas de allá de los lados y de La Aguja, y por ahí cogieron ellos. Las lanchas ya venian vacias, ya venian las lanchas grandes, ya venian nada más, los que venían manejando, unos 5 que venían en las 5 lanchas de a dos.

Después llegaron los periodistas como a las 9:00 de la mañana de aquí, de Santa Marta y le dimos unos datos y eso era una bajadera de muertos por allá, eso eran las 7:00 de la noche y todavía estaban llevando muertos para Sitio Nuevo; ahi mataron un primo, un tio y gracias a Dios que en la casa no llegó la lancha, nada más llegó la primera vez que nos embarcamos y después cuando nos dejaron en la plaza yo me vine por el agua y después cuando salieron no llegaron más sino que se dieron vuelta en las cuatro esquinas y dijeron esas palabras jaqui no hay competencia, vamos que está de día!, eso fue lo que yo alcancé a ver"25.

\section{MEMORIAS RESILIENTES: EL PODER DEL RECUERDO Y EL RECUERDO COMO PODER}

Durante mucho tiempo la ciencia sicológica coadyuvo de una forma directa a que la victima siguiera siendo víctima.

25 Entrevista realizada a un sobreviviente de la masacre del Morro en Nueva Venecia corregimiento de Ciénaga-Magdalena el día 20 de marzo de 2010.
El paradigma de la victimologia ${ }^{26}$ se constituye en el modelo dominante en la forma de tratar a las personas que sufrían cualquier problema. Prácticamente se hace una carrera de víctima:

"En consecuencia, no se trata de decir: "usted está herido, por lo tanto esta perdido", si no "usted está herido: ¿Qué va a hacer con esta herida? ¿Va usted a gemir, a llorar? ¿Va usted a permanecer prisionero del pasado? ¿Va usted a buscar la manera de vengarse? ¿Va usted a buscar el modo de hacer una carrera de víctima, tal y como lo proponen casi todas las sociedades? O por el contrario, con nuestra ayuda y su trabajo, ¿vamos los dos a comenzar a poner en obra un proceso de reparación y de reanudación del desarrollo?" 27.

De ahí la importancia de des-victimizar y de transcender la condición misma de víctima. Empoderar a la victima a través de sus propios relatos para que sea capaz de asumir su condición y a partir de ella proyectarse y reinventarse a sí mismo, es decir hacer resiliencia a través de los relatos de la memoria.

Visto desde esta óptica, la resiliencia es una apuesta por el poder de renovación interior que poseen las personas. Conceptualmente la resiliencia es entendida como:

"... la capacidad que tiene un ser humano (niño, adolescente, adulto), a pesar de sus dificultades personales (fisicas, mentales y psíquicas), para intuir y crear, en circunstancias desfavorables o en un entorno destructor, respuestas que le hacen posible no dejarse atrapar por las circunstancias $y$ dificultades personales ni por las condiciones del entorno sino por el contrario, proponer y realizar comportamientos que le permiten una vida con menos sufrimiento y encontrar un lugar en su medio ambiente, lo cual le permite desarrollar sus capacidades y anhelos"28.

26 SELIGMAN, Walter. La autentica felicidad. Ediciones B. Barcelona. 2002.

27 CYRULNIK, Boris. La resiliencia: desvictimizar la víctima. Editora Feriva. Cali. 2006. p. 36

$28 \quad$ Ibíd. p. 213. 
Sobre la conexión entre resiliencia y memoria, Cyrulnik nos orienta:

"La hipermemoria de los que han conocido un trauma constituye en unos casos una secuela $y$ en otros un punto fuerte de la personalidad, dependiendo del uso que permitan darle los contextos familiares y culturales. Cuando el entorno impide reorganizar esta memoria, los sujetos se ven aprisionados por el pasado. Las imágenes que quedan impregnadas en sus cerebros, debido a la extrema emoción provocada en su día por el acontecimiento, explican la reactivación de las figuras aterradoras en las que piensan durante el día y que regresan por la noche en forma de pesadillas. Sin embargo, cuando la familia, el barrio o la cultura dan al herido ocasión de expresarse, esa hipermemoria alimenta con precisión ciertas representaciones de ideas, de producciones artísticas o de compromisos filosóficos que, al dar sentido a su vida de hombres magullados, les brindan un precioso factor de resiliencia" ${ }^{29}$.

El recuerdo narrado es instaurado como una sublimación del sujeto que tiende a generar una resiliencia. Las narraciones resignifican el presente y le dan poder a la víctima. El recuerdo es instaurado como un mecanismo de poder que brinda autonomía y autoelección. Aquí cumple un papel destacado la narración, la voz de la victima que rememora, como lo plantea nuevamente Cirulnik:

"No solo hablo, sino que tengo el dominio de mi palabra y me convierto progresivamente en sujeto de mi palabra; soy capaz de decir: "Yo soy aquel que conoció tal adversidad, sufrió de tal manera y supero ese infortunio de este modo". En ese momento se constituye la identidad narrativa de aquel que fue herido. Constatamos que hay alli un enorme tutor de resiliencia muy eficaz que es la narratividad. Yo tengo el traumatismo: la resiliencia no dice que el traumatismo no tiene ningún valor; el traumatismo es una muerte

29 CYRULNIK, Boris. El amor que nos cura. Gedisa. Barcelona. 2006. p. 120. psíquica parcial de la cual se puede volver metamorfoseado" 30 .

Finalmente, se enfatiza en que el recuerdo que se convierte en un poder personal, se direcciona a la parte externa, al mundo de la vida del sujeto, para refundar de forma resiliente, el poder del recuerdo.

Veamos el siguiente fragmento:

"Yo, ahora después de eso que yo tuve, yo le he pedido fuerzas a Dios para acabar de ayudar a mis hijos, yo hago dulces, esas fueron mis primeras terapias, yo tenía bastante amigas ahi en el mercado porque yo vendía pescado, me puse a vender unos pescaitos y ya después que pasó lo que pasó me puse a vender los pescaos y las amigas me decían...pero...un día que fui porque yo no salía a ninguna parte, y me decían, pero este a ti sola no te ha pasado eso hermana, o sea me daban consejos, como dárselos yo a ella, nunca les decía como a ellas nunca les ha pasado, sino que yo también puedo darle consejos, yo estoy en lo mismo y yo le he dado consejos a personas que también les ha pasado lo mismo, a mi sola no me ha pasado esto y yo siento cuando a una madre le pasa un caso de éstos ¿porque a mi me ha pasado? $y$ antes de pasarme yo me condolia bastante $y$ decía: ¿será que a mi me va a pasar Señor, perdóname? Porque yo me condolía mucho de las cosas que pasan, ya después yo empecé a regar dulces y los pelaos decían que no, pero ya él tenía como 5 años de estar desaparecido, tengo como 3 años de estar trabajando ya el dulce otra vez de nuevo" ${ }^{\text {"31. }}$.

\section{PRESENTIFICACIÓN DE LA MEMORIA O DE CÓMO RECORDAR TRANSFORMA}

George Orwell (1993) en su distopia, "1984", había planteado los peligros que enfrenta la memoria, en particular el problema de la

$30 \quad$ Ibíd. p. 50.

31 Entrevista realizada el día 17 de abril de 2010 a una madre victima de la violencia. 
reescritura de la memoria y sobre todo la desaparición de la misma. En su metáfora de los agujeros de la memoria, Orwell es claro al mostrarnos como los detentadores del poder pueden alterar significativamente el pasado y destruir los rastros de este, en un proceso de reescritura de la memoria constante:

"Este proceso de continua alteración no se aplicaba solo a los periódicos, sino a los libros, revistas, folletos, carteles, programas, peliculas, bandas sonoras, historietas para niños, fotografias..., es decir, a toda clase de documentación o literatura que pudiera tener algún significado político o ideológico" 32 .

Orwell es enfático en mostrarnos el problema del palimpsesto: "Toda la historia se convertía así en un palimpsesto, raspado y vuelto a escribir con toda la frecuencia necesaria" ${ }^{33}$.

Este palimpsesto es escrito desde múltiples perspectivas pero es claro que la dominante es la de los bloques hegemónicos, que a través de las diversas posibilidades mediáticas, nos terminan mostrando, distorsionando y recreando, una sola historia: la de los vencedores.

La mayoría de las ocasiones esta historia se divide en dos: buenos y malos. De ahí que cada época construya sus propios fantasmas, construya en los imaginarios sociales un fantasma con el cual todos debemos enfrentarnos para lograr la cohesión social: comunismo, narcotráfico, guerrilla, terrorismo y demás. Estos fantasmas posibilitan que la memoria se pierda en los hornos crematorios de los agujeros de la memoria.

A pesar de la moda de los estudios de la memoria $^{34}$, y de las incesantes reescrituras, el

$32 \quad$ ORWELL, George. 1984. RBA. Barcelona. 1993. p. 37

33 Ibíd. p. 37.

34 Díaz, Carlos, et al. "Hacia la comprensión de universos Psico-Culturales. Las fuentes vivas: memoria y narración". Ob. Cit. palimpsesto de la memoria de las víctimas del conflicto permanece y se niega a desaparecer, algunas veces alimentado por el dolor y algunas veces postergada. Pero al adentrarnos en este estudio, lo que se persigue es una lectura hermenéutica de este palimpsesto, para trabajar con las víctimas de la violencia, ese pasado presente.

Cuando se instaura el discurso de la modernidad, se erige el gran metarrelato del futuro. La sociedad occidental se invento sobre los futuros posibles, sobre el mejor mundo por venir, hoy, después de la gran crisis de los grandes metarrelatos, tenemos el imperativo en la postmodernidad o mejor aún, la tardo modernidad, de rehacer el pasado y de presentificar las huellas simbólicas del mismo, que como marcas alimentan el dolor de las víctimas del conflicto armado, en el Departamento del Magdalena.

Esta presentificación es entendida como la posibilidad de rehacer el pasado desde el sujeto mismo, de rememorar, no solo por rememorar, sino por rebelarse a la historia oficial, tal y como lo ejemplifica Saramago con el corrector editorial, que solo con el cambio de una palabra, transforma la historia ${ }^{35}$, y se resignifica así mismo. Es decir la memoria se debe presentificar para construir resiliencia. En la perspectiva de Diaz y Amador:

"Rememorar es reconocer en la condición humana, una particularidad que opera mediante el deseo del recuerdo, pero también, a través del inocultable sufrimiento de presentificar lo ocurrido. En ambos casos, las memorias oficiales inciden en la imagen del mundo que habita las subjetividades, subjetividades que se encuentran en medio de fuerzas históricas, cuyas posibilidades de sostenerse en el tiempo dependen de procesos narrativos, en tanto ser y estar en el momento $y$ que requieren de una particular reafirmación ontológica en la que la vida y lo humano se

SARAMAGO, José. Historia del cerco de Lisboa. Casa editorial El tiempo. Bogotá. 2000. 
correspondan. Frente a la persistencia contemporánea de los arrebatos fundamentalistas se hace necesario contribuir a generar mecanismos para tramitar la memoria que posibiliten controvertir $y$ conmover las practicas $y$ representaciones que continúan permitiendo la vorágine de sangre que padecemos en Colombia" ${ }^{36}$.

La memoria puede transformar realidades y hacer resiliencia. Veamos este relato de una víctima de los paramilitares, que proyecta el problema del dolor de las personas que presencian actos de masacres.

“... eso sí no le sé decir, porque era a las dos de la madrugada y como yo sufro de los nervios, yo me puse mal yo me iba era a tirar al agua y mis hijos me aguantaban, no lo haga amaita, no lo haga, no lo haga, porque si la ven por el agua pueden decir que es alguna persona escapándose y la pueden matar; bueno, y yo con los nervios hasta me orinaba del mismo nervio que yo tenía, yo no sabia ni que era lo que tenía, cuando ya mataron a mi compadre, mataron a otros dos ahi mismo, quedaron en la puerta, en el sardinel uno y en la otra puerta de mi compadre, en el piso.

De ahí salieron para la iglesia, ahi en la iglesia mataron como a 10 que habian, los pusieron a todos en la orilla y todos en el pretil de la iglesia y ahí, iban dándole.

... yo escuché, yo nada más sentía el ipra, pra, pra, pra, pra! y la gente dando gritos, hasta los sesos quedaban pegados en la pared de la iglesia, por que la iglesia está en tierra, esa es una iglesia linda que está en tierra. Bueno y la gente dando gritos y la gente cerrando puertas y otros se tiraban al agua. Yo tuve un sobrino que se tiró al agua y casi que se ahoga; allá cogieron, fuera del Morro, como eso es hondo, se iban ahogando y las hijas mías, me amarraron y yo de los nervios, yo me orinaba solita y yo no sabía qué era lo que tenía, porque eso fue una masacre grande que llegó a esa hora..." 37 .

$36 \quad$ Ibíd. p. 94.

37 Entrevista realizada el día 20 de marzo a una observadora de la masacre de paramilitares en Nueva Venecia, corregimiento de Ciénaga Magdalena.

\section{LOS VISIBLES INVISIBLES: LA RESIGNIFICACIÓN DE LA MEMORIA COMO UNA CATARSIS DE LAS VICTIMAS}

Es común que los medios tiendan a generar invisibilidad en las víctimas de la violencia. Bourdieu señala este proceso como propio del accionar de los periodistas y en particular como propio de la televisión. Él denomina el proceso como un ocultar mostrando y un mostrar ocultando.

"La televisión puede hacer que una noche, ante el telediario de las ocho, se reúna más gente que la que compra todos los diarios franceses de la mañana y de la tarde juntos. Si un medio de esas características suministra una información para todos los gustos, sin asperezas, homogeneizada, cabe imaginar los efectos politicos y culturales que de ello pueden resultar. Es una ley que se conoce a la perfección: cuanto más amplio es el público que un medio de comunicación pretende alcanzar, más ha de limar sus asperezas, más ha de evitar todo lo que pueda dividir, excluir, más ha de intentar no escandalizar a nadie, como se suele decir, no plantear jamás problemas o sólo problemas sin trascendencia" ${ }^{\prime 3}$.

Estos procesos sutiles de enmascaramiento de la realidad ya habían sido señalados por autores como $\mathrm{Mcombs}^{39}$ con el concepto de Agenda Setting, al referirse a los diversos mecanismos mediante el cual los medios masivos de comunicación organizan los contenidos de lo que debe ser visto. Este orden, y el tiempo dedicado a cada fragmento de la realidad (que no necesariamente se corresponde con lo que es real), organiza los asuntos que deben ser atendido por los políticos y por el pensamiento de los públicos. Así mismo Ana

38 BORDIEU, Pierre. Sobre la televisión. Ob. Cit. p. 64

39 McCombs, Maxwell, et al. "Los temas y los aspectos: explorando una nueva dimensión de la Agendasetting". En: Comunicación y Sociedad. No. 8 (1). 1995. 
María Miralles ${ }^{40}$, demuestra como lo público es enmarcado en lo publicable y se confunde lo público con lo relacionado con el Estado, pero lo público que debe emanar de los públicos, no se tiene en cuenta a la hora de abordar las realidades ${ }^{41}$.

En ultimas lo público no es publicable, no se adapta a las exigencias del marketing, en pocas palabras las victimas no son un producto fácil de mercadear, solo cuando las victimas se convierten en victimarios, se produce una transformación en las condiciones del producto a vender ${ }^{42}$.

José Antonio Camargo ${ }^{43}$ demostró mediante una investigación de análisis de contenido en los periódicos más importantes del Magdalena, que cada vez que los desplazados eran reseñados por estos medios, la figura de la víctima no aparecía en el medio como tal, es decir siempre aparecía el funcionario público, lo que hacía parecer que la víctima como tal no existía. Siempre el tema era mostrado desde lo que hacia el Estado para la víctima y casi nunca desde los requerimientos de la victima hacia el estado $^{44}$.

El investigador Ismael Roldan, es tajante cuando afirma:

"La violación de los derechos básicos de las victimas es solo una parte de su situación, porque también es importante reconocer en ellas la particularidad de su cultura y de su dolor. Los prejuicios, los estereotipos y el desconocimiento de la victima hacen que no se respete su pluralismo, sino que se tenga una visión uniforme, fortalecida por el manejo que de ellas hacen los medios de

40 MIRALLES, Ana María. Periodismo, opinión pública y agenda ciudadana. Editorial Norma. Bogotá. 2002.

41 Ibídem.

42 Ibídem.

43 CAMARGO, José Antonio. Voces y silencios del desplazamiento forzado en la ciudad de Santa Marta. Ob. Cit.

44 Ibídem. comunicación. Esto conlleva a desdibujarla, y finalmente su olvido por parte de la sociedad" 45.

Frente a esto no queda más que la memoria como posibilidad de catarsis y de trascendencia. Así mismo la memoria como una opción de visibilizar lo invisibilizado. Como lo planteaba Fals Borda ${ }^{46}$, es necesario confrontar la historia oficial con la historia desde los protagonistas, desde abajo, en canales que se confrontan, que discurren pero que se cuestionan.

\section{A MANERA DE CONCLUSIÓN: LA RECONSTRUCCIÓN DE LA MEMORIA COMO LIBERACIÓN DEL DOLOR}

Los trabajos sobre la memoria son oportunos para resarcir a las víctimas y para resignificar el dolor. Para que la catarsis que produce la narración se materialice en transformación del sujeto y de su entorno. Para que la víctima no se quede siendo víctima y sea capaz de trasformar, desde la resiliencia, su condición de víctima.

"En oposición, estos enfoques han vindicado una memoria contra hegemónica, que no se referencia en la historia de las sociedades nacionales, sino que tiene para si una historicidad propia, amalgamada en tiempos y espacios culturalmente construidos, en capacidad de plantear de manera critica la resistencia de las minorías étnicas y de los grupos culturales ante las pretensiones de arrasamiento $y$ de invisibilidad de la historia nacional' 47 .

Al hacer investigación sobre la memoria, visibilizamos a los tradicionalmente invisibilizados,

45 Roldán, Ismael. "El estado actual de las victimas en Colombia: la búsqueda de la verdad". En: Revista Colombiana de Psiquiatría. Vol. XXXVI/No 1/2007. p. 43.

46 FALS BORDA, Orlando. Retorno a la tierra. Historia doble de la costa. Carlos Valencia editor. Bogotá. 1986.

47 SERNA, Adrian. Memorias en crisoles. Propuestas metodológicas y estrategias para los estudios de la memoria. Universidad Distrital Francisco José de Caldas. Bogotá. 2009. p. 22. 
para que estos grupos excluidos puedan tener una voz y ser escuchados. Esta es la condición clave de resignificar la memoria, recordar para reconfigurar y reordenar.

"Los trabajos de la memoria incluyen mecanismos de transmisión, para hacer que los acontecimientos recordados se vuelvan significativos para aquellos que no los vivieron en carne propia, lo cual tiene profundas implicaciones politicas en el nivel personal y en el colectivo-publico" 48 .

Respecto a estos niveles, Molano Agrega:

"En el primero, en la subjetividad de la memoria, el reconocimiento y reconstrucción-recodificación de experiencias dolorosas pasadas, están ligadas a maneras de dignificación personal. En el segundo, en el de las practicas colectivas, el recordar impulsa a la defensa de un tipo de instituciones, prácticas sociales y espacios sociales comprometidas con la no repetición del dolor" 49.

Es decir, los trabajos sobre la memoria dan instrumentos simbólicos para que los sujetos sean capaces de asumir de una forma contrahegemónica su lucha contra el olvido del Estado, contra la amnesia colectiva y contra la posible repetición de su tragedia en otras escalas y niveles.

Cyrulnik es bastnate enfatico cuando insta a: "Quien ha sufrido un trauma se somete o se libera de su historia utilizándola. Esa es su disyuntiva: o se ve obligado a repetir o forzado a liberarse" 50 .

Esta investigación se centra en esa perspectiva, la de sensibilizar a la opinión pública visibilizando a las víctimas, empoderandolas

48 Molano, Frank. "Reflexiones metodológicas de segundo orden en la reconstrucción colectiva de las memorias de y con las victimas de estado". En: SERNA, Adrian. Memorias en crisoles. Universidad Distrital Francisco José de Caldas. Bogotá. 2009. p. 31.

49 Ibídem.

50 CYRULNIK, Boris. El amor que nos cura. Ob. Cit. p. 120. y a través del relato, de la comunicación de su relato personal, de la palabra, de la exploración de sus sentimientos y tragedias, se intenta encontrar el brillo de la fuerza de la resiliencia como liberación personal y social.

Y como recordar es cuestión de poder, es bueno tener presente la cita que hace Hannah Arendt tomada de Isak Dinesen:

"Todas las personas pueden soportarse si las ponemos en una historia o contamos una historia sobre ellas" ${ }^{15}$.

\section{BIBLIOGRAFÍA}

ACEVES, Jorge. Técnicas de investigación y manipulación. Práctica y estilos de investigación en la historia oral contemporánea. Historia y fuente Oral. Barcelona. 1994

ARENDT, Hannah. La condición humana. Paidos. Barcelona. 2005

BAUMAN, Zygmunt. Vida de consumo. Fondo de Cultura Económica. México. 2003

Bello, Martha, et al. "Desplazados, migrantes y excluidos: actores de las dinámicas urbanas". En: CUBIDES, Fernando, et al (Ed.). Desplazados, migraciones internas y reestructuraciones territoriales. Centro de Estudios Sociales. Bogotá. 2001

Desplazamiento forzado. Dinámicas de guerra, exclusión y desarraigo. Universidad Nacional de Colombia. Bogotá. 2004

BORDIEU, Pierre. Sobre la televisión. Anagrama. Barcelona 1984

BUSHNELL, David. Colombia una Nación a pesar de sí misma. Planeta. Bogotá. 1994

CAMARGO, José Antonio. Voces y silencios del desplazamiento forzado en la ciudad de Santa

51 ARENDT, Hannah. La condición humana. Paidos. Barcelona. 2005. p. 205. 
Marta. Universidad Sergio Arboleda. Santa Marta. 2007.

CARREÑO SUÁREZ, Laura Sofía, et al. Estudios diagnósticos para el fortalecimiento integral de los proyectos de asistencia humanitaria de emergencia para personas internamente desplazadas. Corporación Avre. Bogotá. 2002.

CONSULTORÍA PARA LOS DERECHOS HUMANOS Y EL DESPLAZAMIENTO. DEPARTAMENTOS DE LLEGADA AÑOS 2006 - 2007. Fuente: Sistema de Información sobre desplazamiento Forzado y Derechos Humanos - SISDHES. Reporte: febrero 13 de 2008.

COMISION INTERAMERICANA DE DERECHOS HUMANOS. Informe No 88/06. Petición 1306-05. Organización de Estados Americanos. 2006.

CORTE CONSTITUCIONAL. Sentencia T 0-25 de 2004. M.P Manuel José Cepeda. 22 de Enero de 2004.

CYRULNIK, Boris. El amor que nos cura. Gedisa. Barcelona. 2006.

CYRULNIK, Boris. La resiliencia: desvictimizar la víctima. Editora Feriva. Cali. 2006.

DANE. Informe de coyuntura económica Regional Departamento del Magdalena. 2008.

Díaz, Carlos, et al. "Hacia la comprensión de universos Psico-Culturales. Las fuentes vivas: memoria y narración". En: SERNA, Adrian. Memorias en crisoles. Universidad Distrital Francisco José de Caldas. Bogotá. 2009.

DOING BUSINESS en Colombia. Banco Mundial y la corporación financiera Mundial. 2010.

EQUIPO NIZKOR. Informe de la comisión de organismos de Derechos humanos sobre la masacre en la ciénaga grande de Santa Marta. Bogotá. 2000.
Estrada, Fernando. "Ciénaga Grande: viaje al corazón de la barbarie". En: Revista Número. No 28. 2000. Bogotá.

FACIOLINCE, Héctor Abad. Traiciones de la memoria. Alfaguara. Bogotá. 2009.

FALS BORDA, Orlando. Retorno a la tierra. Historia doble de la costa. Carlos Valencia editor. Bogotá. 1986.

GALEANO, María Eumelia. Estrategias de investigación social cualitativa. El giro en la mirada. La Carreta. Medellín. 2004.

LATORRE IGLESIAS, Edimer. De aplazados a desplazados: la realidad de los derechos de las personas en condición de desplazamiento forzoso en la ciudad de Santa Marta. Fondo de publicaciones Universidad Sergio Arboleda. Bogotá. 2009.

McCombs, Maxwell, et al. "Los temas y los aspectos: explorando una nueva dimensión de la Agenda-setting". En: Comunicación y Sociedad. No. 8 (1). 1995.

MEDELLIN LOZANO, Fernando. El desplazamiento forzado en Colombia. Defensoría del Pueblo. Bogotá. 2003.

MIRAlles, Ana María. Periodismo, opinión pública y agenda ciudadana. Editorial Norma. Bogotá. 2002.

Molano, Frank. "Reflexiones metodológicas de segundo orden en la reconstrucción colectiva de las memorias de y con las victimas de estado". En: SERNA, Adrian. Memorias en crisoles. Universidad Distrital Francisco José de Caldas. Bogotá. 2009.

Montero, Maritza. "Historias de vida: memoria individual y colectiva". En: Revista Acta sociológica. Numero 1. Enero-Abril de 1990. Bogotá.

ORWELL, George. 1984. RBA. Barcelona. 1993.

PULIDO, Rodrigo. Abordaje hermenéutico de la investigación cualitativa. Editorial Universidad Cooperativa de Colombia. Bogotá. 2007. 
RODRÍGUEZ, Ferney. Patrimonio y personalidad jurídica de los desplazados del Distrito de Barranquilla. Universidad Simón Bolívar. Barranquilla. 2008.

Roldán, Ismael. "El estado actual de las victimas en Colombia: la búsqueda de la verdad". En: Revista Colombiana de Psiquiatría. Vol. XXXVI/No 1/2007.

SAMPIERI, Roberto. Metodología de la investigación. Mc Graw Hill. México. 2006.

Sandoval, Marbel. "Desplazados: una historia sin contar". En: Universitas Humanistica. $\mathrm{N}^{\mathrm{o}}$ 47. Pontificia Universidad Javeriana. Bogotá. 1999.
SARAMAGO, José. Historia del cerco de Lisboa. Casa editorial El tiempo. Bogotá. 2000.

SARTORI, Giovanni. El homo videns: La sociedad teledirigida. Santillana-Taurus. Madrid. 1998.

SELIGMAN, Walter. La autentica felicidad. Ediciones B. Barcelona. 2002.

SERNA, Adrian. Memorias en crisoles. Propuestas metodológicas y estrategias para los estudios de la memoria. Universidad Distrital Francisco José de Caldas. Bogotá. 2009.

URIBE, María Victoria. Antropología de la inhumanidad. Un ensayo interpretativo sobre el terror en Colombia. Norma. Bogotá. 2004. 
